\title{
Inserción de las enfermeras residentes en Salud Pública en el Programa Médico de La Familia: reporte de la experiencia
}

\author{
Cavalcanti-Valente,Geilsa Soraia1, Alves-Frota da Costa Mariana²
}

\section{RESUMEN}

Se trata de un reporte de experiencia en la residencia de Salud Pública de la Escuela de Enfermería Aurora Afonso Costa - Universidade Federal Fluminense. Tiene como objetivo reflexionar sobre la inserción de una enfermera residente en Salud Pública en el Programa Salud de la Familia en el municipio de Niterói-RJ. Brasil. La residencia en Enfermería en Salud Comunitaria prepara a las enfermeras para ser competente, calificada e interesada en los temas sociales que rodean a la persona y su familia, lo que contribuye favorablemente en la situación de salud

Palabras clave: enfermería, salud pública, salud de familia. Brasil. (Fuente DeCs BIREME).

\section{Insertion of Nurse Resident in collective health on the Program family medical: Experience report}

\begin{abstract}
This is an experience report on Residency Public Health School of Nursing Aurora Afonso Costa - Universidade Federal Fluminense - RJ. Aims to reflect upon the insertion of a resident nurse in public health in the Family Health Program in the city of Niterói-RJ. Brasil. It appears that the Residency in Community Health Nursing prepares nurses to be a competent, qualified and interested in social issues that surround the individual and their family, contributing favorably in health status.
\end{abstract}

Key words: nursing, public health, family health. Brazil (Source DeCs BIREME).

\section{Inserção do enfermeiro Residente em Saúde Coletiva no Programa Médico de Família: Relato de Experiência}

\section{RESUMO}

Trata-se de relato de experiência na Residência em Saúde Coletiva da Escola de Enfermagem Aurora de Afonso Costa - Universidade Federal Fluminense - RJ. Tem o objetivo de refletir sobre a inserção do enfermeiro residente em saúde coletiva no Programa Médico de Família do município de Niterói-RJ. Brasil. Constata-se que a Residência em Enfermagem em Saúde Coletiva prepara o enfermeiro a ser um profissional competente, capacitado e interessado pelas questões sociais que circundam o indivíduo e sua família, contribuindo favoravelmente na situação de saúde.

Palavras chave: Enfermagem; Saúde Coletiva; Saúde da Família. Brasil. (Fuente DeCs BIREME).

Doutora em Enfermagem. Professora do Departamento de Fundamentos de Enfermagem e Administração da Escola de Enfermagem Aurora de Afonso Costa - Universidade Federal Fluminense. Niteroi (RJ).

Enfermeira especialista em Saúde Coletiva pela Escola de Enfermagem Aurora de Afonso Costa da Universidade Federal Fluminense (EEAAC/ UFF). Mestranda em Saúde Coletiva pelo Instituto de Estudos em Saúde Coletiva pela Universidade Federal do Rio de Janeiro (IESC/UFRJ). 


\section{INTRODUÇÃO}

A Residência em Enfermagem é uma prática recente no Brasil. Sabe-se que esta prática surgiu para que enfermeiros recém-graduados tivessem uma capacitação melhor e consequentemente resultaria em uma melhor assistência ao paciente, família e comunidade. Caracteriza-se por treinamento em serviço, possibilitando ao enfermeiro o crescimento profissional, além da obtenção do título de especialista na área de escolha (1). Desenvolvese em regime de dedicação exclusiva, colocando o enfermeiro residente em contato contínuo com a prática, possibilitando o acompanhamento dos pacientes, oferecendo paralelamente as modalidades de ensino, pesquisa e extensão, com duração de dois anos. Para a conclusão do Curso de Especialização nos Moldes de Residência Enfermagem é exigida uma monografia que deverá ser apresentada à banca examinadora (2).

A Residência em Enfermagem é uma especialização com $80 \%$ das atividades voltadas à prática e $20 \%$ à teoria e possui rígido esquema de treinamento que pretende colocar enfermeiros melhor preparados no mercado de trabalho ${ }^{1}$. Os enfermeiros recém-formados se sentem inseguros, principalmente em relação às técnicas de enfermagem. Neste sentido, a residência proporciona a esses profissionais a ampliação dos saberes e competências adquiridos na graduação, tornando-os mais capacitados à realizarem técnicas com embasamento científico, crítico e reflexivo.

A residência em questão neste artigo trata-se do Curso de Pós-Graduação em Nível de Especialização sob a forma de Treinamento em Serviço nos Moldes de Residência em Enfermagem, vinculada á Universidade Federal Fluminense (UFF). Dentre as unidades de treinamento em serviço, está o Programa Médico de Família (PMF) de Niterói - RJ. O PMF possui desde a sua concepção o foco na Saúde da Família, além da vigilância à saúde, caráter preventivo e de promoção da saúde. Este Programa entrelaça muito bem nos campos da Saúde Coletiva, pois assemelha as diretrizes das questões sociais que circundam o paciente e sua família no contexto do processo saúde-doença. Diante do exposto, tem-se como objeto de estudo: a inserção do enfermeiro residente em Saúde Coletiva.

\section{OBJETIVO}

Refletir sobre a inserção do enfermeiro residente em saúde coletiva da Universidade Federal Fluminense (UFF) no Programa Médico de Família de Niterói - RJ.

\section{METODOLOGIA}

Trata-se de uma pesquisa qualitativa do tipo relato de experiência, a partir da percepção de uma residente em Saúde coletiva e uma docente do curso de Especialização nos moldes de Residencia da Escola de Enfermagem Aurora de Afonso costa - Universidade Federal Fluminense, localizada no município de Niteroi - RJ. A pesquisa qualitativa surge diante da impossibilidade de investigar e compreender, por meios estatísticos, alguns fenômenos voltados para a percepção, intuição e a subjetividade. Está direcionada para a investigação dos significados das relações humanas, em que suas ações são influenciadas pelas emoções e/ou sentimentos aflorados diante das situações vivenciadas no dia-a-dia $(3,4)$.

Relato de experiência é um estudo que revela as ações do indivíduo como agente humano e como participante da vida social. O informante conta sua história e o pesquisador pode desvendar os aspectos subjetivos da cultura e da organização social, das instituições e dos movimentos sociais $(5,3)$.

\section{CONTRIBUIÇÃO DO ENFERMEIRO RESIDEN- TE EM SAÚDE COLETIVA NO PROGRAMA MÉDICO DE FAMÍLIA (PMF)}

Na década de 70 foi discutido no Brasil pela primeira vez, o programa de residência em enfermagem. O primeiro programa de residência em enfermagem foi o de pediatria, criado em São Paulo no ano de 1961. Este programa tinha como objetivo capacitar melhor o profissional enfermeiro recém-formado (1).

O segundo programa foi implantado pela Universidade Federal da Bahia em 1973 na área de enfermagem no Brasil: Universidade Federal de Pernambuco em 1974; Universidade Federal Fluminense em 1975; Instituto Nacional de Assistência Médica e Previdência Social em 1976; Escola Nacional de Saúde Pública da Fundação Osvaldo Cruz em 1977; Universidade do Estado do Rio de Janeiro em 1978; Hospital Barros Barreto no Pará em 1977 e a Universidade Federal da Paraíba em 1978 (1).

Em 1978 foi realizado o Seminário sobre Residência Enfermagem, pela Associação Brasileira de Enfermagem seção Rio de Janeiro. Neste Seminário, foram definidos os seguintes objetivos da residência: aprimorar a prática profissional nas áreas de especialização e elevar o padrão de assistência nas instituições (2). A Comissão Permanente de Educação da Associação Brasileira de Enfermagem (ABEN) - Nacional realizou em Salvador, 
uma Oficina intitulada «Residência em Enfermagem no Brasil», em sequência da deliberação do I Seminário Nacional de Educação em Enfermagem, em maio do mesmo ano, no Rio de janeiro. Nesses eventos surgiram as primeiras discussões relacionadas à Residência em Enfermagem como alternativa para suprir as deficiências da graduação e suprir déficit de recursos humanos nos serviços de saúde (6).

O Conselho Federal de Enfermagem (COFEN) prosseguiu com as discussões e em setembro do mesmo ano, ao final do Seminário Nacional do Sistema COFEN/COREN's (Conselhos Regionais de Enfermagem) realizado em Salvador, emitisse um documento sobre a residência. Deste documento, resultou o Anteprojeto de Lei, dispondo sobre a Residência em Enfermagem, criando a Comissão Nacional de Residência de Enfermagem e outras providências (6). Em 1996, o Deputado Paulo Rocha (Partido dos Trabalhadores - Pará) apresentou o Projeto Lei n. ${ }^{\circ}$ 2.264/ 1996, cuja redação final apresenta de forma sucinta a proposta do anteprojeto inicial, da Residência em Enfermagem. Ocorre também um movimento dos órgãos dirigentes da Enfermagem no Brasil na implementação desta modalidade como pós-graduação (6).

Atualmente, não há uma Lei que regulamente o Programa de Residência em Enfermagem no Brasil, porém, existe o Projeto n 2264 de 1996 que estabelece a residência de enfermagem como um programa que seja capaz de abranger a assistência e pesquisa científica (7).

Vale salientar que as residências multiprofissionais e em área profissional da saúde, criadas a partir da promulgação da Lei n 11.129 de 2005, são orientadas pelos princípios e diretrizes do Sistema Único de Saúde (SUS), a partir das necessidades e realidades locais e regionais, e abrangem as profissões da área da saúde, a saber: Biomedicina, Ciências Biológicas, Educação Física, Enfermagem, Farmácia, Fisioterapia, Fonoaudiologia, Medicina Veterinária, Nutrição, Odontologia, Psicologia, Serviço Social e Terapia Ocupacional. (Resolução CNS $\left.n^{0} 287 / 1998\right)$

Na Residência em Enfermagem em Saúde Coletiva, iniciada no ano de 2010, na Universidade Federal Fluminense, a partir de uma integração com a Escola de Enfermagem Alfredo Pinto, Universidade Federal do Estado do Rio de Janeiro, segundo o seu projeto politico pedagógico, o ensino teórico não deve ser desvinculado da prática, pois este subsidiará a assistência, pesquisa e extensão, influenciando direta ou indiretamente na postura do enfermeiro em suas atividades. As disciplinas selecionadas para compor a grade curricular visam aprimorar conhecimentos básicos nas áreas de Enfermagem:

Primeiro ano: Relações Interpessoais; Tópicos Especiais em Enfermagem; Política, Planejamento e Programas; Metodologia da Assistência de Enfermagem; Metodologia da Pesquisa I; Epidemiologia e Didática.

Segundo ano: Seminário de Produção Científica; Administração; Tópicos Avançados e Produção Científica.

Os professores que compõem o curso são enfermeiros pós-graduados, mestres e doutores, do quadro permanente da Escola de Enfermagem Aurora de Afonso Costa da Universidade Federal Fluminense (EEAAC/UFF). Ocorre também a presença de profissionais convidados que elucidam a prática assistencial de cada unidade de treinamento em serviço. Na Residência de Enfermagem em Saúde Coletiva da Universidade Federal Fluminense, os residentes são acolhidos e supervisionados pelos preceptores que se caracterizam pelos enfermeiros do campo prático e pelos professores da Escola de Enfermagem Aurora de Afonso Costa da UFF. As disciplinas de Relações Interpessoais e Tópicos Especiais em Enfermagem são as iniciais do curso, o que considerase de uma importância significativa para a inserção do enfermeiro ao campo prático. Estas disciplinas auxiliam na percepção sobre questões éticas e de postura diante da profissão e abordagem do enfermeiro residente ao paciente.

A disciplina de Relações Interpessoais proporciona ao enfermeiro maior segurança na abordagem ao cliente e sua família. Sabemos que por muitas vezes o tratamento, cura e reabilitação do paciente pode ser prejudicado pelas falhas na comunicação entre enfermeiro-paciente. Assim, esta disciplina propõe ao enfermeiro o método do saber ouvir, além de desmistificar preconceitos e adequar a assistência de enfermagem a realidade e cultura de determinada pessoa. Além da abordagem ao paciente, na referida disciplina também é abordada a relação interpessoal no processo de trabalho. Este fato é algo tão assustador para os enfermeiros, pois os mesmos se sentem inseguros por se tornarem líderes de equipe ao saírem da graduação.

Já a disciplina de Tópicos Especiais em Enfermagem apresenta as unidades de treinamento em serviço para que o residente se aproxime ao máximo da assistência que será prestada. São também relembrados alguns conceitos já desenvolvidos ao longo da graduação, que 
são indispensáveis na assistência do enfermeiro residente. Percebe-se então que as disciplinas são de extrema importância para a prática assistencial do enfermeiro residente. Este fato comprova-se com a maior segurança com que o enfermeiro realiza a sua assistência. $\mathrm{Na}$ verdade, as disciplinas são um suporte teórico e científico em que auxilia o enfermeiro residente a prestar uma assistência de enfermagem de qualidade ao paciente.

Para atuar neste âmbito, é necessário compreender melhor a unidade de treinamento em serviço do residente, neste caso, o Programa Médico de Família (PMF). Este Programa foi baseado no modelo cubano, implantado em 1992, como modelo de medicina de família implantando os princípios e diretrizes do Sistema Único de Saúde (SUS) ${ }^{8}$. Concebe sua proposta de saúde da família como uma estratégia de equidade, uma vez que seja implantado nas áreas de maior risco social e ambiental do município, privilegiando moradores com renda familiar mensal inferior a cinco salários mínimos, ocorre adscrição da clientela ao serviço (8). Dentro do PMF há uma co-gestão do modelo, existência de organização comunitária com vínculos locais e perspectivas organizativas. A contratação dos profissionais se dá pela Associação de Moradores regidos pela CLT (Consolidação das Leis Trabalhistas) e se caracterizam por coordenadores, supervisores, médicos e auxiliares de enfermagem. Os módulos são divididos em setores, cuja população seja cadastrada (8).

A equipe básica do PMF é formada pelo médico e auxiliar de enfermagem. Há cerca de três anos, após a inserção dos residentes, o enfermeiro e os agentes comunitários de saúde foram incorporados ao Programa. No atual momento, há uma adaptação dessa nova fase do PMF, visto que o enfermeiro não pertencia à equipe básica que permanece no módulo. E nesta nova fase, o enfermeiro residente também é inserido no módulo (8). Percebe-se que há uma adaptação por parte dos enfermeiros e por parte da própria equipe de trabalho. $\mathrm{O}$ auxiliar de enfermagem era o responsável pela assistência de enfermagem e administração do módulo. Com a chegada do enfermeiro, o auxiliar passou a realizar técnicas mais simples, sem se preocupar com a gerência. O enfermeiro foi designado para ser o gerente da unidade e ser responsável por todos os acontecimentos. O enfermeiro residente inserido nesta unidade deve se adaptar e juntamente com o enfermeiro criar estratégias que melhorem a qualidade de vida da comunidade.

O enfermeiro contemporâneo busca desempenhar seu papel com objetivo de contribuir com as modificações no cenário da saúde no país (2). A contribuição do enfermeiro residente no PMF do município de Niterói se dá, necessariamente, no resgate as práticas educativas, sendo individual nas consultas de enfermagem ou na realização de grupos educativos. Como qualquer programa da atenção básica, o PMF visa à promoção da saúde e prevenção de doenças. Portanto, a realização de consulta de enfermagem e a realização de grupos de risco, como gestante, hipertensos e diabéticos caracterizam a melhoria da qualidade de vida dessas pessoas, além de diminuir os agravos causados pelas patologias.

Embora o enfermeiro ainda encontre algumas limitações para agir no programa Médico de Família no município de Niterói - RJ acredita-se que, a partir da inserção dos residentes de Enfermagem em Saúde Coletiva neste cenário como campo de práticas, este profissional tenha conquistado mais espaço, vislumbrando-se na atualidade a mudança do referido programa para um modelo hibrido de assistência à saúde, onde o enfermeiro passa a fazer parte mais efetivamente, nas ações práticas e gerenciais, em consonância com o preconizado pelo SUS.

\section{CONSIDERAÇÕES FINAIS}

Percebeu-se que a inserção do enfermeiro residente no PMF promove diversas contribuições, tanto para a evolução do modelo de assistência à saúde, quanto para melhor capacitação do profissional, tornando-o competente para o mercado de trabalho e resultando em uma assistência de enfermagem de qualidade para o paciente, família e comunidade. Práticas educativas como grupos muitas vezes deixados de lado, são resgatadas pelo enfermeiro residente na unidade de saúde da família, o que contribui severamente para a qualidade de vida da comunidade, tendo em vista os benefícios para a profissão, cliente, profissional e instituição de saúde.

Espera-se, com este relato de experiência, trazer contribuições aos profissionais de enfermagem do Brasil como um todo, e em especial os do município de Niteroi RJ, no sentido de assegurar à clientela uma assistência digna, humanizada, sistematizada e de qualidade, com a plena atuação do profissional enfermeiro.

Neste sentido, constata-se que a residência em enfermagem em saúde coletiva prepara o enfermeiro a ser um profissional competente, capacitado e interessado pelas questões sociais que circundam o indivíduo e sua família, contribuindo favoravelmente na situação de saúde. 


\section{REFERENCIAS BIBLIOGRÁFICAS}

1. Franco GP, Barros ALBL, Martins LAN. Qualidade vida e sintomas depressivos em residentes de enfermagem. Rev Latino-am Enferm 2005; 13 (2): 139-144.

2. Aguiar BGC, Moura VLF, Sória DAC. Especialização nos moldes de residência em enfermagem. Rev Bras Enferm, Brasília (DF) 2004; 57 (5): 555-559.

3. Figueiredo, Nébia Maria Almeida de. Método e metodologia na pesquisa científica. Ed. Yendis. São Paulo, 2009.

4. Minayo, M.C.S. (Org.). Pesquisa social: teoria, método e criatividade. Rio de Janeiro: Vozes, 1994.

5. Cardoso, L. da S. Exercícios e notas para formular uma pesquisa. Rio de Janeiro: Papel Virtual, 2000. 74.

6. Barros ALBL, Michel JLM. Curso de especialização em enfermagem - modalidade residência: experiência de implantação em um hospital-escola. Rev. latinoam. enferm - Ribeirão Preto - 2000 ; 8 (1) : 5-11.
7. Carbogim FC, Santos KB, Alves MS, Silva GA. Residência em Enfermagem: a experiência de Juiz de Fora do ponto de vista dos residentes. Rev. APS, Juiz de Fora, 2010;13(2):245-249.

8. Hübner LCM, Franco TB. O Programa Médico de Família de Niterói como Estratégia de Implementação de um Modelo de Atenção que Contemple os Princípios e Diretrizes do SUS. PHYSIS: Rev. Saúde Coletiva, Rio de Janeiro, 2007; 17 (1): 173-191.

\section{Correspondencia}

Geilsa Soraia Cavalcanti Valente

Escola de Enfermagem Aurora de Afonso Costa - Universidade Federal Fluminense.

Dirección: Rua Miguel de Frias, 9, Icaraí, Niterói, RJ, Brasil

Correo electrónico: geilsavalente@yahoo.com.br

Forma de citar este artículo: Cavalcanti-Valente,Geilsa Soraia, Alves-Frota da Costa Mariana. Inserción de las enfermeras residentes en Salud Pública en el Programa Médico de La Familia: reporte de la experiencia. Rev. enferm Herediana.2014;7(1):5054. 